\title{
Prevalence and Antibiotic Resistance Mechanisms of Methicillin-Resistant Staphylococcus aureus isolates from Selected Hospitals in Ashanti Region, Ghana.
}

\section{Crystal Ngofi Zumbi}

Kwame Nkrumah University of Science and Technology

Vivian Etsiapa Boamah ( $\sim$ etsiapa@yahoo.com )

Kwame Nkrumah University of Science and Technology

Yaw Duah Boakye

Kwame Nkrumah University of Science and Technology

Hayford Odoi

University of Health and Allied Sciences

Christian Agyare

Kwame Nkrumah University of Science and Technology

\section{Research Article}

Keywords: Methicillin-resistant Staphylococcus aureus, multidrug resistance, antibiotics, mecA gene, mecC gene, efflux pumps

Posted Date: June 22nd, 2021

DOI: https://doi.org/10.21203/rs.3.rs-602638/v1

License: (c) (1) This work is licensed under a Creative Commons Attribution 4.0 International License.

Read Full License 
1 Title: Prevalence and Antibiotic Resistance Mechanisms of Methicillin-Resistant

2 Staphylococcus aureus isolates from Selected Hospitals in Ashanti Region, Ghana

3 Author/co-authors contact details:

4 Crystal Ngofi Zumbi ${ }^{1}$, Vivian Etsiapa Boamah ${ }^{1 *}$, Yaw Duah Boakye ${ }^{1}$, Hayford Odoi ${ }^{2}$,

5 Christian Agyare ${ }^{1}$

6

${ }^{1}$ Microbiology Section, Department of Pharmaceutics, Faculty of Pharmacy and Pharmaceutical

Sciences, Kwame Nkrumah University of Science and Technology, Kumasi, Ghana

$9{ }^{2}$ Department of Pharmaceutical Microbiology, School of Pharmacy, University of Health and Allied

10 Sciences, Ho, Volta Region, Ghana

*Corresponding author (Dr. V. E. Boamah); Email: veboamah.pharm@knust.edu.gh; etsiapa@yahoo.com;

14 Tel: +233244981167

15

\section{Corresponding author email and affiliation}

17 Dr. V. E. Boamah

18 Email: etsiapa@yahoo.com veboamah.pharm@knust.edu.gh;

19 Affiliation: Microbiology Section, Department of Pharmaceutics, Faculty of Pharmacy and Pharmaceutical

20 Sciences, Kwame Nkrumah University of Science and Technology, Kumasi 
ABSTRACT

31 Background: Antibiotic resistance in bacteria has long been recognized as a major health

32 problem occurring worldwide. The emergence of methicillin-resistant Staphylococcus

33 aureus (MRSA) remains a global health problem. MRSA is reported as one of the leading

34 pathogens involved in increased rates of morbidity and mortality amongst patients in

35 Ghana. This study determined the prevalence and resistance mechanisms of MRSA

36 isolated from patients in selected hospitals in the Ashanti Region of Ghana. Antibiograms

37 of the isolates were determined using the Kirby-Bauer disk diffusion method. Antibiotic

38 resistance genes (mecA and $m e c C$ ) were detected and efflux pump activity assessed using

39 polymerase chain reaction (PCR) and microbroth dilution methods, respectively.

40 Results: Out of 626 samples obtained from patients, S. aureus was identified in 68, 41 representing $10.9 \%$. Multidrug resistance (MDR) was observed in $46(67.6 \%)$ of the $S$.

42 aureus isolates of which 28 (60.9\%) were Methicillin Resistant Staphylococcus aureus

43 (MRSA). The MRSA isolates showed higher susceptibility to trimethoprim-

44 sulfamethoxazole (50\%) and higher resistance to oxacillin and cefoxitin (100\%). mec $A$

45 gene was identified in $9(32.1 \%)$ of the MRSA isolates whereas mecC gene was absent in

46 all the isolates. The isolates did not exhibit any multiple efflux pump activities.

47 Conclusion: The prevalence of MDR-MRSA in $S$. aureus infections at healthcare

48 facilities in the Ashanti region was found to be high. The presence of the mecA gene was

49 identified as a possible mechanism responsible for resistance in the MRSA isolates.

51 Keywords: Methicillin-resistant Staphylococcus aureus, multidrug resistance, 52 antibiotics, $m e c A$ gene, mec $C$ gene, efflux pumps. 


\section{Background}

54 Bacterial infections are a major cause of morbidity and mortality among humans all over

55 the world (1). For several decades, antibiotics have increased the survival rate of patients

56 (2). However, the emergence of resistant bacteria has become a significant problem

57 within the health sector (3).

58 Staphylococcus aureus infection is reported as a menace in hospitals in most parts of the

59 world (4). In Ghana, it has been reported as one of the most occurring MDR pathogen

60 amongst patients reporting to regional and teaching hospitals for clinical care (2). The

61 anterior nares and external skin surfaces of humans are frequently colonized by

62 staphylococci causing skin and soft tissue infections and invasive infections (5).

63 Methicillin resistant Staphylococcus aureus (MRSA) is a strain resistant to methicillin

64 and/or oxacillin (6). The occurrence and spread of MRSA in communities and health

65 facilities are particularly worrisome as reports have indicated that MRSA is the leading

66 pathogen involved in high rates of morbidity and mortality amongst infected patients (7).

67 The mecA gene in MRSA is responsible for the synthesis of an altered penicillin-binding

68 protein, PBP2a, known to have a lower affinity for $\beta$-lactam antibiotics (8). Until the

69 discovery of the mecC gene, detection of mecA in $S$. aureus was regarded as the gold

70 standard for the diagnosis of MRSA infections (9). The gene sequence of mecC is about

$7170 \%$ identical to that of mec $A$ and at the amino acid level, it is $63 \%$ identical to PBP2a.

$72 \mathrm{MecC}$-harboring $S$. aureus is often missed during phenotypic testing because it contains a

73 type XI staphylococcal cassette chromosome with genetic makeup similar to oxacillin-

74 susceptible MRSA (10), hence its detection requires genetic or molecular techniques. 
75 Some studies have however reported of MRSA genotypes that possess neither mec $A$ nor

$76 \quad C$ genes; suggesting that other mechanisms could be involved in resistance to oxacillin

77 and MRSA expression. Such mechanisms could include mutation in the PBP genes,

78 hyper production of $\beta$-lactamases and multidrug efflux pump activity $(10,11)$. In Ghana,

79 very few studies have reported on the mechanisms responsible for resistance in MRSA.

80 In addition, continuous monitoring of the prevalence and susceptibility patterns of MRSA

81 in health facilities in Ghana is necessary for effective management and control of MRSA

82 infections (12). Hence this study aimed to determine the prevalence and susceptibility

83 patterns of $S$. aureus isolates including MRSA and identify possible mechanisms

84 responsible for the resistance among the isolates in selected health facilities in Ghana.

85

86 RESULTS

87 Distribution of MRSA isolates amongst the hospitals

88 A total of 626 samples were collected from urine, wound and nasal swabs of patients

89 visiting the selected hospitals. The samples were obtained from the hospitals as follows:

90184 samples from Komfo Anokye Teaching Hospital (KATH), 163 from Agogo

91 Presbyterian Hospital, 117 from Manhyia Government Hospital, 109 from Kwame

92 Nkrumah University of Science and Technology (KNUST) Hospital and 53 samples from

93 Suntreso Government Hospital (Table 1).

94

95 Based on growth on culture media, biochemical characteristics and SPA gene detection, a

96 total of $68(10.9 \%)$ Staphylococcus aureus strains were isolated from the 626 samples

97 collected. Of the $68 \mathrm{~S}$. aureus isolates, 46 (67.6\%) were multi-drug resistant; non- 
98 susceptible to at least one antibiotic in three or more antibacterial categories (13) (Table

$991)$.

100 Seventeen $(37.0 \%, \mathrm{n}=17 / 46)$ of the MDR S. aureus were isolated from Agogo hospital, $10114(30.4 \%, n=14 / 46)$ from KATH, $13(28.3 \%, n=13 / 46)$ from KNUST hospital and 1

$102(2.2 \%, n=1 / 46)$ each from Manhyia and Suntreso hospitals. Thirty-one $(67 \%, n=31 / 46)$ of

103 the MDR S. aureus isolates were identified from urine samples whereas $15(32.6 \%$, $104 \mathrm{n}=15 / 46$ ) were obtained from nasal samples of the patients. None of the MDR S. aureus 105 isolates was obtained from wound samples (Table 1).

106

107 Of the 68 S. aureus isolates, $28(41.2 \%, \mathrm{n}=28 / 68)$ were MRSA and all of these isolates 108 were multidrug resistant. MRSA isolates were more prevalent in the samples from 109 KNUST hospital $(56.3 \%, n=9 / 16)$ compared to those from Agogo $(48 \%, n=12 / 25)$ and 110 KATH $(31.8 \%, \mathrm{n}=7 / 22)$. MRSA isolates were more prevalent in nasal samples $(55.6 \%$, $111 \mathrm{n}=10 / 18)$ compared to urine samples $(36.7 \%, \mathrm{n}=18 / 49)$. No MRSA isolate was obtained

112 from wound swab samples (Table 1). MRSA isolates showed high resistance (60 to $113100 \%$ ) to all selected antibiotics and were more susceptible to trimethoprim114 sulfamethoxazole $(50 \%, \mathrm{n}=14 / 28)$ (Table 1, Figure 1). MRSA isolates from KATH 115 showed relatively low resistance to the different antibiotics compared to those from 116 Agogo and KNUST hospitals (Table 1).

118 Six of the MRSA isolates were resistant to all the eight antibiotics tested. Erythromycin 119 and ciprofloxacin showed relatively higher activity against the MRSA isolates from 120 KATH whiles Trimethoprim-sulfamethoxazole was comparatively more active against 
121 stains isolates from KNUST and Agogo. The most frequent patterns of resistance among

122 the MRSA isolates were ERY-OXA-CIP-CHL-SXT-TET-CN-FOX (21.4\%) and ERY-

123 OXA-CIP-SXT-TET-CN-FOX (10.7\%) (Table 2).

124

125 Mechanism of resistance in multidrug resistant $M R S A$ isolates

126 Presence of resistant genes (mec $A$ and $m e c C$ ) in multidrug resistant $S$. aureus strains

127 Out of the twenty-eight (28) MRSA isolates, $9(32.1 \%)$ had the mec $A$ gene present. None

128 of the isolates possessed the mecC gene (Figure 2).

129

130 Efflux pump activity amongst MDR MRSA isolates

131 The MICs of ciprofloxacin against the isolates ranged from 0.8 to $12.8 \mu \mathrm{g} / \mathrm{mL}$. In the

132 presence of reserpine, no reduction in the MICs were recorded. The MICs of ampicillin

133 against the isolates ranged from 3.2 to $12.8 \mu \mathrm{g} / \mathrm{mL}$. Again, no reduction in the MICs were

134 recorded in the presence of reserpine, indicating the absence of multiple efflux pump

135 activity in the isolates.

137 Discussion

138 Increasing antibiotic resistance among pathogenic bacteria calls for more studies on the 139 prevalence and resistance mechanisms among these bacteria (1). Continuous monitoring 140 of prevalence, susceptibility patterns and resistance mechanisms of pathogenic bacteria, 141 including MRSA, in health facilities is also necessary for effective management and 142 control of bacterial infections (12). 
143 Most of the reported surveillance on antimicrobial resistance of pathogens often involve

144 samples obtained from large regional or teaching hospitals $(2,12,14)$ with very few from

145 smaller hospitals. In this study, samples were collected from a regional teaching hospital,

146 four primary hospitals including one university hospital and three district hospitals in

147 order to report on antimicrobial resistance at the district levels as well.

148 A review conducted by Bustamante (14) in 2011 indicated MRSA prevalence of 23 to

$14973 \%$ from different clinical samples across Europe, whereas in Ghana, some studies have

150 reported prevalence of MRSA ranging from 28 to $34.8 \%(2,12,15,16)$. In this study, a

151 prevalence of $41.2 \%$ was recorded. This is higher than that previously reported in Ghana.

152 The difference could be due to the difference in sources of the samples.

154 Some studies define MRSA as S. aureus isolates resistant to oxacillin, possession of 155 either mecA or $C$ gene or a latex agglutination test for the detection of PBP2a (17-20). In 156 this study, however, MRSA was defined as S. aureus isolates resistant to cefoxitin (30 $157 \mu \mathrm{g}$, as suggested by the CLSI guidelines)(21) and such could lead to differences in the 158 prevalence values observed. In as much as these assays are correct, over the years, the 159 laboratory screening guidelines are updated and for example, oxacillin disk testing is no 160 longer reliable as stated in the CLSI guidelines (21). Also, the specific detection of the 161 mec genes or PBP2a could allow for some isolates to be missed. This is true because 162 some studies have identified MRSA isolates which did not possess any of these genes and 163 others had mutations, hence allowing for such isolates to be missed $(11,22)$.

164 Most of the MDR MRSA isolates were identified in urine samples (18, 64.3\%) compared 165 to the nasal samples $(10,35.7 \%)$. However, $35.7 \%$ is of a relatively high prevalence in 
166 nasal samples and this could lead to transmission to other patients at health care facilities

167 as reported by Amissah et al (23). Also, performing nasal-swab screening could assist

168 clinicians in tailoring down the choices of antibiotics to use (24).

169

170 The antibiograms of the MRSA isolates revealed an appreciable level of resistance to the

171 test antibiotics (Tables 1 and 2, Figure 1). The isolates were mostly resistant to oxacillin

172 and cefoxitin (100\%), tetracycline (82.1\%) and chloramphenicol (75\%). Similarly, high

173 resistance of MRSA to $\beta$-lactams (oxacillin) has been reported (12). Majority (50\%) of

174 the isolates were, however, susceptible to trimethoprim-sulfamethoxazole and this

175 findings similar to that reported by Egyir et al, $(25,26)$.

176

177 In this study, mecA gene was detected in nine (9) of the MRSA isolates (32.1\%), 178 representing approximately $13.2 \%$ of the total $S$. aureus isolates. Another study in Ghana 179 reported a $28 \%$ prevalence of $m e c A$ genes in $S$. aureus strains isolated from various 180 samples from patients at the Burns Unit of the Korle-Bu Teaching Hospital, Ghana (7) 181 and this is higher than the $13 \%$ prevalence of $m e c A$ genes among patients in this study. 182 The difference in $m e c A$ prevalence among the $S$. aureus isolates could probably be due to 183 the fact that patients who suffer from burns and those on admission could be more 184 susceptible to MRSA infections (27).

185

186 mec $C$ genes were not detected in any of the $S$. aureus strains in this study. Globally, the 187 prevalence of mecC genes in $S$. aureus is quite low; with a reported prevalence of 
188 between $0.4 \%$ and $0.7 \%(28,29)$. The mecC genes have not yet been identified and 189 reported in Ghana.

191 Apart from mecA and mecC genes, other factors such as the presence of efflux pumps

192 have been identified to contribute to the development of resistance in S. aureus (30),

193 hence the MICs of ciprofloxacin in the presence and absence of an efflux pump inhibitor

194 (reserpine) was done to determine the presence of the efflux pump activities among the

195 resistant isolates not containing the mecA gene. There was no change in the MIC of the

196 ciprofloxacin and ampicillin in the presence of reserpine, suggesting very limited efflux

197 activity in the evolution of MDR in the MRSA strains.

198

199 Among the 28 MRSA isolates, 19 (67.9\%) had neither mecA, mecC nor enhanced efflux 200 pumps activity. This shows that, other mechanisms may be responsible for resistance 201 evolution in the MRSA isolates. Some studies have suggested mutations in the PBP 202 genes, hyper production of $\beta$-lactamases and polymorphisms in the mec genes may be 203 responsible for the resistance (31-33). There is a need to identify other possible 204 mechanisms that may be responsible for the multidrug resistance in the S. aureus isolates 205 especially in MRSA strains. This way, new drugs could be formulated and/or synthesized 206 to tackle these pathways.

208 Conclusion

209 The prevalence of $S$. aureus isolates among the collected samples was $10.9 \%$ and $41.2 \%$ 210 of these isolates were MRSA. The isolates were highly resistant to most of the reference 
211 antibiotics except for trimethoprim-sulfamethoxazole. The presence of the mecA gene

212 was identified as one of the mechanisms responsible for multidrug resistance in the $S$.

213 aureus isolates. There is a need to continuously identity and monitor the level of

214 resistance of $S$. aureus isolates in other health facilities and community acquired $S$.

215 aureus infections in Ghana to enhance and improve the treatment of infections with $S$.

216 aureus including MRSA.

218 Abbreviations

219 ATCC American Type Culture Collection

220 CHRPE Committee on Human Research, Publication, and Ethics

221 CLSI Clinical and Laboratory Standards Institute

222 DNA Deoxyribonucleic Acid

223 KATH Komfo Anokye Teaching Hospital

224 KNUST Kwame Nkrumah University of Science and Technology

225 MDR Multidrug resistance

226 MIC Minimum inhibitory concentration

227 MRSA Methicillin-resistant Staphylococcus aureus

228 MSA mannitol salt agar

229 MTT 3-(4,5-dimethylthiazol-2-yl)-2, 5-diphenyltetrazolium bromide

230 PBP penicillin-binding protein

231 PBS phosphate-buffered saline

232 PCR polymerase chain reaction

233 SPA Staphylococcus aureus Protein A 
235 Methods

236 Ethical consideration

237 The study was approved by the Committee on Human Research, Publication, and Ethics

238 (CHRPE) the Kwame Nkrumah University of Science and Technology (KNUST),

239 Kumasi, with reference number CHRPE/AP/354/17. Permission and informed consent

240 were sought from the various hospital authorities, subjects and their caregivers. In

241 general, the study was performed in accordance with the Declaration of Helsinki (42).

242

\section{Study sites}

244 Five hospitals (Komfo Anokye Teaching Hospital, Kwame Nkrumah University of

245 Science and Technology (KNUST) Hospital, Manhyia Government Hospital, Suntreso

246 Government Hospital and Agogo Presbyterian Hospital), all located in the Ashanti

247 Region, Ghana, were selected for the study. They comprised of one teaching hospital and

248 four primary hospitals including a University hospital and 3 district hospitals.

\section{Sample collection}

251 Participants of the study were patients of all ages, who were suspected of having bacterial

252 infections and were required to undergo clinical investigations at the microbiology

253 laboratories, and patients who reported to the wound unit for wound dressing. Sterile

254 cotton swabs were used to swab the anterior nares and wounds of the participants. The

255 swabs were separately placed in $2 \mathrm{~mL}$ quantities of freshly prepared $10 \mathrm{~mL}$ sterile

256 nutrient broth and labelled appropriately. Urine samples were collected into $30 \mathrm{~mL}$ sterile 
257 containers and labelled appropriately. The samples were then transported with $12 \mathrm{~h}$ to the

258 Microbiology Laboratory in the Department of Pharmaceutics, Faculty of Pharmacy and

259 Pharmaceutical Sciences, Kwame Nkrumah University of Science and Technology for 260 analysis.

261

\section{Isolation of $\boldsymbol{S}$. aureus strains}

263 Samples collected were placed into $10 \mathrm{~mL}$ nutrient broth and incubated at $37^{\circ} \mathrm{C}$ for $24 \mathrm{~h}$.

264 After incubation, a loopful was streaked on $20 \mathrm{~mL}$ mannitol salt agar (MSA) plate. The

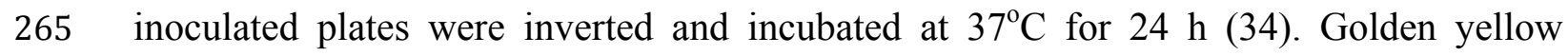

266 colonies on MSA were aseptically fished out and inoculated into $10 \mathrm{~mL}$ nutrient broth

267 and incubated at at $37^{\circ} \mathrm{C}$ for $24 \mathrm{~h}$. Gram staining and biochemical tests including

268 hemolysis on blood agar, catalase and coagulase tests were performed on the $24 \mathrm{~h}$ broth

269 culture to confirm the isolates as presumptive $S$. aureus, using $S$. aureus ATCC 25923 as

270 the positive control organism (35).

271

272 Confirmation of Presumptive $S$. aureus isolates by Polymerase Chain Reaction

273 (PCR)

274 The DNA of presumptive $S$. aureus isolates was extracted using the boiling lysis method 275 as previously described by Meacham et al. (36) with some modifications. Single colonies 276 of the presumptive $S$. aureus isolates, cultured on $20 \mathrm{~mL}$ nutrient agar plates, were 277 transferred into $100 \mu \mathrm{L}$ of phosphate-buffered saline (PBS), centrifuged at $15000 \mathrm{x} \mathrm{g}$ for $2785 \mathrm{~min}$ at $25^{\circ} \mathrm{C}$ and the supernatant discarded. One hundred microliters $(100 \mu \mathrm{L})$ of PBS 279 was then added, vortexed and the solution heated at $95^{\circ} \mathrm{C}$ for $10 \mathrm{~min}$ and cooled at $-20^{\circ} \mathrm{C}$ 
280 for $5 \mathrm{~min}$. The mixture was again centrifuged at $15,000 \mathrm{x} \mathrm{g}$ for $5 \mathrm{~min}$ at $25^{\circ} \mathrm{C}$. The 281 supernatant was collected into Eppendorf tubes and stored at $-20^{\circ} \mathrm{C}$ until used. Using the 282 forward primer spa 1113-F (5'-TAA AGA CGA TCC TTC GGT GAGC-3') and reverse 283 primer spa 1514-R (5'-CAG CAG TAG TGC CGT TTG CTT-3') (37), polymerase chain 284 reaction was carried out using a thermal cycler (Gene Amp, ThermoFisher Scientific, 285 Waltham, MA, USA USA). The PCR reaction was carried out in a final volume of $25 \mu \mathrm{L}$ 286 containing $2 \mu \mathrm{L}$ of DNA template, $12.5 \mu \mathrm{L}$ of One Taq master mix, $2 \mu \mathrm{L}(0.8 \mu \mathrm{M})$ of 287 each primer and $6.5 \mu \mathrm{L}$ of nuclease-free water. The PCR consisted of an initial 288 denaturation at $94^{\circ} \mathrm{C}$ for $5 \mathrm{~min}$, followed by 35 cycles of denaturation at $94^{\circ} \mathrm{C}$ for $30 \mathrm{sec}$, 289 annealing at $60^{\circ} \mathrm{C}$ for $1 \mathrm{~min}$ and extension at $72^{\circ} \mathrm{C}$ for $1 \mathrm{~min}$ and a final extension at $72^{\circ} \mathrm{C}$ 290 for $10 \mathrm{~min}$. The PCR products were separated on $1.5 \% \mathrm{w} / \mathrm{v}$ agarose gel at $100 \mathrm{~V}$ and 291 visualized under UV light (16). Amplicon size ranged from 180 to $600 \mathrm{bp}$ (38).

\section{Antibiotic sensitivity testing}

294 Antibiotic susceptibility of the S. aureus isolates was determined using the Kirby-Bauer 295 agar disk diffusion method (39) following guidelines from the Clinical and Laboratory 296 Standards Institute (CLSI) (21). A loopful of the confirmed S. aureus was streaked on 20 $297 \mathrm{~mL}$ of nutrient agar and incubated at $37^{\circ} \mathrm{C}$ for $24 \mathrm{~h}$. Cells from five (5) to ten (10) well298 isolated colonies were picked with an inoculating loop and emulsified into $2 \mathrm{~mL}$ sterile 299 saline. The suspension was standardized to $0.5 \mathrm{McFarland}$ either by diluting with more 300 saline or addition of more bacteria cells. A sterile cotton-wool swab was dipped into the 301 suspension, pressed firmly against the inner walls of the test tube to remove excess liquid, 302 and then used to inoculate the surface of $20 \mathrm{~mL}$ Mueller-Hinton agar plate by continuous 
303 swabbing of the plate while rotating at an angle of $60^{\circ}$ (approximately three times). With

304 the aid of a disk dispenser, eight antibiotic disks from eight antibiotic classes including

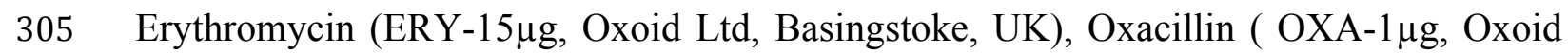

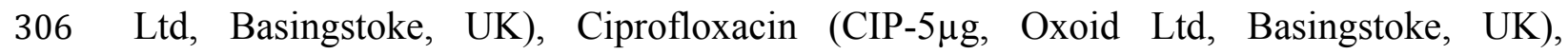
307 Chloramphenicol (CHL-30 $\mu$ g, Oxoid Ltd, Basingstoke, UK), Trimethoprim-

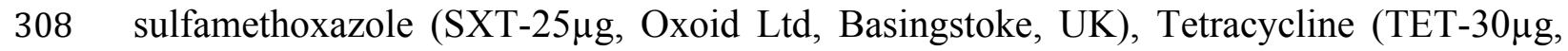

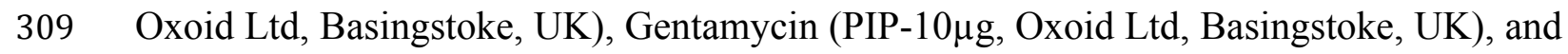
310 cefoxitin (FOX-100 $\mu$ g, Oxoid Ltd, Basingstoke, UK) were delivered on the surface of the 311 inoculated agar plate and incubated at $37^{\circ} \mathrm{C}$ for $18 \mathrm{~h}$. Zones of growth inhibition were 312 measured in millimeters using a millimeter rule. The experiment was carried out in 313 triplicate and the mean zones of inhibition were compared to breakpoint values provided 314 by the Clinical and Laboratory Standards Institute (CLSI) (21).

316 Detection of $m e c A$ and $m e c C$ antibiotic resistant genes in S. aureus.

317 PCR amplification of mecA and $m e c C$ genes was performed following procedures 318 described by Boamah et al. (13) using the primers mecA-F (5`-ACG GTA ACA TTG 319 ATC GCA ACG-3'), Mec A-R (5`-GGC CAA TTC CAC ATT GTT TCG-3’) and 320 mecCF (5'-GAA AAA AAG GCT TAG AAC GCC TC-3’), mecC-R (5'-GAA GAT 321 CTT TTC CGT TTT CAG C-3'), respectively. Two microliters (2 $\mu \mathrm{L})$ of DNA template 322 was added to a final volume of $25 \mu \mathrm{L}$ containing $12.5 \mu \mathrm{L}$ of One Taq master mix, $2 \mu \mathrm{L}$ $323(0.8 \mu \mathrm{M})$ of each primer and $6.5 \mu \mathrm{L}$ of nuclease--free water. The PCR consisted of an 324 initial denaturation at $94^{\circ} \mathrm{C}$ for $5 \mathrm{~min}$, followed by 35 cycles of denaturation at $94^{\circ} \mathrm{C}$ for $32530 \mathrm{sec}$, annealing at $59^{\circ} \mathrm{C}$ and $55^{\circ} \mathrm{C}$ for $1 \mathrm{~min}$ for mecA and mecC genes, respectively and 
326 extension at $72^{\circ} \mathrm{C}$ for $1 \mathrm{~min}$ and a final extension at $72^{\circ} \mathrm{C}$ for $10 \mathrm{~min}$. The PCR products

327 were separated using a $1.5 \% \mathrm{w} / \mathrm{v}$ agarose gel at $100 \mathrm{~V}$ and visualized under UV light.

328 Amplicon sizes were detected at 176 and 138 bps, respectively.

330 Detection of efflux pump activity

331 The efflux pump activity of the $S$. aureus isolates was assessed using the efflux pump 332 inhibition assay (41) utilising the microdilution method. The MICs of ampicillin and 333 ciprofloxacin were determined in the presence and absence of reserpine using 96-well 334 microtiter plates (40). The inoculum was prepared by suspending 5 to 7 well-isolated 335 colonies in sterile normal saline to the density of 0.5 McFarland standard. Using a 336 dilution factor of 2 , different concentrations of the antibiotics were prepared from 0.8 to $337 \quad 12.8 \mu \mathrm{g} / \mathrm{mL}$. One hundred microliters $(100 \mu \mathrm{L})$ of double strength nutrient broth was 338 dispensed into 5 wells. This was followed by the addition of appropriate volumes of 339 ciprofloxacin for a given concentration $(500 \mu \mathrm{g} / \mathrm{mL})$ which was serially diluted by 2 -fold 340 into each well, followed by the introduction of $20 \mu \mathrm{L}$ of the inoculum. Sterile water was 341 then added to make a final volume of $200 \mu \mathrm{L}$. The plates were incubated for $24 \mathrm{~h}$ at $37^{\circ} \mathrm{C}$ 342 after which $20 \mu \mathrm{L}$ of $1.25 \mathrm{mg} / \mathrm{mL} 3-(4,5$ dimethylthiazol-2-yl)-2, 5-diphenyltetrazolium 343 bromide (MTT) was added to the wells. Wells that showed purple colour after 30 min 344 incubation at $37^{\circ} \mathrm{C}$, indicated bacteria growth and those that remained yellowish indicated 345 inhibitory activity. The MICs of ampicillin and ciprofloxacin were redetermined in the 346 presence of $50 \mu \mathrm{g} / \mathrm{mL}$ concentration of the plant alkaloid reserpine (reserpine stock 347 solution was prepared to $500 \mu \mathrm{g} / \mathrm{mL})$. 


\section{Declarations}

\section{$350 \quad$ Ethical consideration}

351 The study was approved by the Committee on Human Research, Publication, and Ethics

352 (CHRPE) the Kwame Nkrumah University of Science and Technology (KNUST), 353 Kumasi, with reference number CHRPE/AP/354/17. Permission and informed consent 354 were sought from the various hospital authorities, subjects and their caregivers. In 355 general, the study was performed in accordance with the Declaration of Helsinki.

357 Data availability

358 All the necessary data on the above study is included in the manuscript.

359 Competing interests

360 The authors declare no competing interest in this study.

$361 \quad$ Funding

362 The study did not receive any external funding. The authors funded from their own 363 pockets.

\section{Author contributions}

365 CNZ carried out the laboratory exercises, data analysis and drafted the manuscript. VEB 366 was involved in the conception, design, and coordination of the studies. YDB and HO 367 participated in the data analysis and editing of the manuscript. CA participated in the 
368 conception, experimental design and analysis of data. All the authors reviewed the 369 manuscript.

371 Acknowledgement

372 We are grateful to management and staff of selected hospitals for the cooperation and

373 support during the project and appreciate the staff the Kumasi Centre for Collaborative 374 Research in Tropical Medicine, Kumasi, Ghana, for their technical assistance provided 375 during the PCR experiments.

376

377

\section{REFERENCES}

380 1. WHO. Antimicrobial resistance. Global Report on Surveillance. World Heal Organ $381 \quad$ [Internet]. 2014;61(3):383-94. Available from:

382 http://www.ncbi.nlm.nih.gov/pubmed/22247201\%5Cnhttp://www.pubmedcentral. 383 nih.gov/articlerender.fcgi? $\operatorname{artid}=2536104 \&$ tool=pmcentrez\&rendertype=abstract

384 2. Newman M, Frimpong E, Asamoah-Adu A, Sampane-Donkor E. Resistance to 385 antimicrobial drugs in Ghana. Infect Drug Resist. 2011;4:215-20.

386 3. Gajdács M, Albericio F. Antibiotic resistance: from the bench to patients. $387 \quad$ Antibiotics. 2019;8(3):8-11.

388 4. Ippolito G, Wenzel RP. Methicillin-resistant Staphylococcus aureus: the superbug. $389 \quad$ Int J Infect Dis. 2010;14(4):7-11.

390 5. Alkhawam H, Sogomonian R, Zaiem F, Vyas N, El-Hunjul M, Jolly J, et al. 
Morbidity and mortality of infective endocarditis in a hospital system in New York City serving a diverse urban population. J Investig Med [Internet]. 2016 Aug 1 [cited 2018 Jun 12];64(6):1118-23. Available from: http://www.ncbi.nlm.nih.gov/pubmed/27206447

6. Gajdács M. The continuing threat of methicillin-resistant Staphylococcus Aureus. Antibiotics. 2019;8(2).

397 7. Amissah NA, Dam L Van, Ablordey A, Ampomah O, Prah I, Tetteh CS, et al. 398 Epidemiology of Staphylococcus aureus in a burn unit of a tertiary care center in 399 Ghana. PLoS One. 2017;12(7):e0181072.

400 8. Becker K, Ballhausen B, Köck R, Kriegeskorte A. Methicillin resistance in 401 Staphylococcus isolates: The "mec alphabet" with specific consideration of mecC, 402 a mec homolog associated with zoonotic S. aureus lineages. Int J Med Microbiol 403 [Internet]. 2014 Oct [cited 2018 Jun 12];304(7):794-804. Available from: 404 http://www.ncbi.nlm.nih.gov/pubmed/25034857

4059 9. Pournajaf A, Ardebili A, Goudarzi L, Khodabandeh M, Narimani T, Abbaszadeh 406 H. PCR-based identification of methicillin-resistant Staphylococcus aureus strains 407 and their antibiotic resistance profiles. Asian Pac J Trop Biomed [Internet]. 2014 408 May [cited 2020 Nov 26];4(Suppl 1):S293-7. Available from:

$409 \quad$ /pmc/articles/PMC4025288/?report=abstract

410 10. BA F. Mec C-harboring methicillin-resistant Staphylococcus aureus: hiding in 411 plain sight. J Clin Microbiol. 2018;56:e01549-17.

412 11. Elhassan MM, Ozbak HA, Hemeg HA, Elmekki MA, Ahmed LM. Absence of the 413 mecA gene in methicillin resistant Staphylococcus aureus isolated from different 
clinical specimens in Shendi City, Sudan. Biomed Res Int. 2015;2015.

415 12. Karikari AB, Frimpong E, Owusu-Ofori A. Methicillin-resistant Staphylococcus

416 aureus among patients in a teaching hospital in Ghana. Int J One Heal [Internet].

4172017 Jul;3:46-9. Available from: http://www.onehealthjournal.org/Vol.3/8.html

418 13. Boamah VE, Agyare C, Odoi H, Adu F, Gbedema S, Dalsgaard A. Prevalence and

419 antibiotic resistance of coagulase-negative Staphylococci isolated from poultry

420 farms in three regions of Ghana. Infect Drug Resist [Internet]. 2017 Jun;Volume

421 10:175-83. Available from: https://www.dovepress.com/prevalence-and-

antibiotic-resistance-of-coagulase-negative-staphylococ-peer-reviewed-article-IDR

423 14. Dora Bustamante N. MRSA: A Global Threat [Internet]. [Texas]: UT

Southwestern Medical School; 2011 [cited 2021 Jun 7]. Available from:

425 https://utswmed-

428 15. Odonkor ST, Newman MJ, Addo KK. Prevalence and antibiotic susceptibility profile of methicillin resistant Staphylococcus aureus in Accra, Ghana. Microbiol ir.tdl.org/bitstream/handle/2152.5/969/BustamanteNirma.pdf?sequence=3\&isAllo wed $=\mathrm{y}$

432 16. Odonkor ST, Addo KK. Evaluation of Three Methods For Detection of Methicillin 433 Resistant Staphylococcus Aureus (MRSA). BioMedSciDirect [Internet]. 2011 [cited 2021 Jun 7];2(4):1031-4. Available from: www.biomedscidirect.com

435 17. Pu W, Su Y, Li J, Li C, Yang Z, Deng H, et al. High Incidence of Oxacillin436 Susceptible mecA-Positive Staphylococcus aureus (OS-MRSA) Associated with 
Bovine Mastitis in China. Zhang Q, editor. PLoS One [Internet]. 2014 Feb 11 [cited 2020 May 11];9(2):e88134. Available from: https://dx.plos.org/10.1371/journal.pone.0088134

440 18. Huse HK, Miller SA, Chandrasekaran S, Hindler JA, Lawhon SD, Bemis DA, et

19. Wu MT, Burnham C-AD, Westblade LF, Dien Bard J, Lawhon SD, Wallace MA, et al. Evaluation of Oxacillin and Cefoxitin Disk and MIC Breakpoints for Prediction of Methicillin Resistance in Human and Veterinary Isolates of Staphylococcus intermedius Group. Richter SS, editor. J Clin Microbiol [Internet]. 2016 Mar;54(3):535-42. Available from: https://jcm.asm.org/content/54/3/535

20. Bard JD, Hindler JA, Gold HS, Limbago B. Rationale for eliminating staphylococcus breakpoints for $\beta$-lactam agents other than penicillin, oxacillin or cefoxitin, and ceftaroline. Clin Infect Dis [Internet]. 2014 [cited 2020 Nov 27];58(9):1287-96. Available from: /pmc/articles/PMC5734619/?report=abstract

21. CLSI. M100 Performance Standards for Antimicrobial Susceptibility Testing A CLSI supplement for global application [Internet]. 29th ed. CLSI, editor. Pennsylvania; 2020 [cited 2021 May 22]. Available from: www.clsi.org.

22. Ba X, Harrison EM, Edwards GF, Holden MTG, Larsen AR, Petersen A, et al. Novel mutations in penicillin-binding protein genes in clinical Staphylococcus 
aureus isolates that are methicillin resistant on susceptibility testing, but lack the mec gene. J Antimicrob Chemother. 2014;69(3):594-7.

462 23. Amissah NA, Buultjens AH, Ablordey A, van Dam L, Opoku-Ware A, Baines SL, et al. Methicillin resistant Staphylococcus aureus transmission in a Ghanaian burn unit: The importance of active surveillance in resource-limited settings. Front Microbiol. 2017;8:1-11.

24. Rioux J, Edwards J, Bresee L, Abu-Ulba A, Yu S, Dersch-Mills D, et al. Nasal2014 Feb 25 [cited 2021 Jun 7];9(2):e89716. Available from: www.plosone.org

474 26. Egyir B, Guardabassi L, Monecke S, Addo KK, Newman MJ, Larsen AR. Methicillin-resistant Staphylococcus aureus strains from Ghana include USA300. J

478 27. Reygaert WC. Antimicrobial resistance mechanisms of Staphylococcus aureus. In: 479 Microbial pathogens and strategies for combating them: science, technology and 480 http://dx.doi.org/10.1016/j.jgar.2014.11.006 education [Internet]. 2013. p. 297-305. Available from: https://www.academia.edu/26269711/Antimicrobial_resistance_mechanisms_of_S taphylococcus_aureus 
483 28. Kerschner H, Harrison EM, Hartl R, Holmes MA, Apfalter P. First report of mecC $484 \quad$ MRSA in human samples from Austria: molecular characteristics and clinical data. 485 New Microbes New Infect [Internet]. 2015 Jan 1 [cited 2018 Aug 18];3:4-9.

$486 \quad$ Available from:

487 https://www.sciencedirect.com/science/article/pii/S2052297514000080

29. Paterson GK, Harrison EM, Holmes MA. The emergence of mecC methicillinresistant Staphylococcus aureus. Trends Microbiol [Internet]. 2014 Jan [cited 2018 Jun 12];22(1):42-7. Available from: http://www.ncbi.nlm.nih.gov/pubmed/24331435

492 30. Jang S. Multidrug efflux pumps in Staphylococcus aureus and their clinical implications. J Microbiol [Internet]. 2016 Jan 5 [cited 2018 Aug 18];54(1):1-8.

31. Ford BA. mecC-Harboring Methicillin-Resistant Staphylococcus aureus: Hiding in

32. Shukla SK, Ramaswamy S V., Conradt J, Stemper ME, Reich R, Reed KD, et al.

Novel Polymorphisms in mec Genes and a New mec Complex Type in

Methicillin-Resistant Staphylococcus aureus Isolates Obtained in Rural Wisconsin. Antimicrob Agents Chemother [Internet]. 2004 Aug [cited 2020 May

503 33. Hiramatsu K, Ito T, Tsubakishita S, Sasaki T, Takeuchi F, Morimoto Y, et al. 
https://icjournal.org/DOIx.php?id=10.3947/ic.2013.45.2.117

507 34. Betty A, Daniel F, Weissfeld S. Bailey and Scott's Diagnostic Microbiology. 2007. $1056 \mathrm{p}$.

509 35. Gajdács M, Urbán E. Epidemiology and resistance trends of Staphylococcus aureus isolated from vaginal samples: a 10-year retrospective study in Hungary. Acta Dermatovenerologica Alp Pannonica Adriat [Internet]. 2019 Dec 30;28(4):143-7. Available from: http://acta-apa.mf.uni-lj.si/journals/actadermatovenerol-apa/papers/10.15570/actaapa.2019.35/actaapa.2019.35.pdf

36. Meacham KJ, Zhang L, Foxman B, Bauer RJ, Marrs CF. Evaluation of Genotyping Large Numbers of Escherichia coli Isolates by Enterobacterial Repetitive Intergenic Consensus-PCR. J Clin Microbiol [Internet]. 2003 Nov 1;41(11):5224-6. Available from: http://jcm.asm.org/cgi/doi/10.1128/JCM.41.11.5224-5226.2003

37. Sun J, Yang M, Sreevatsan S, Davies PR. Prevalence and Characterization of Staphylococcus aureus in Growing Pigs in the USA. Anjum M, editor. PLoS One [Internet]. 2015 Nov 24;10(11):e0143670. Available from: https://dx.plos.org/10.1371/journal.pone.0143670

38. Larsen AR, Stegger M, Sørum M. spa typing directly from a mecA, spa and pvl multiplex PCR assay — a cost-effective improvement for methicillin-resistant Staphylococcus aureus surveillance. Clin Microbiol Infect [Internet]. 2008 Jun 1 [cited 2018 Jun 30];14(6):611-4. Available from: https:/www.sciencedirect.com/science/article/pii/S1198743X14619613 39. Bauer AW, Kirby WMM, Sherris JC, Turck M. Antibiotic Susceptibility Testing 
by a Standardized Single Disk Method. 1966.

530 40. Omoregie R, Airueghionmon DJU, Okonkwo, Airueghionmon U-E, Ibeh, Ogefere HO. Prevalence of multidrug efflux pump requiring ciprofloxacin, ofloxacin and pefloxacin as substrates, among clinical isolates of Pseudomonas aeruginosa. vol 3, 2007.

534 41. Spengler G, Kincses A, Gajdács M, Amaral L. New roads leading to old 535 destinations: Efflux pumps as targets to reverse multidrug resistance in bacteria. Molecules. 2017; 22(3). doi:10.3390/molecules22030468

537 42. World Medical Association declaration of Helsinki: Ethical principles for medical research involving human subjects [Internet]. Vol. 310, JAMA - Journal of the American Medical Association. JAMA; 2013 [cited 2020 Nov 26]. p. 2191-4. Available from: https://pubmed.ncbi.nlm.nih.gov/24141714/ 
Figures

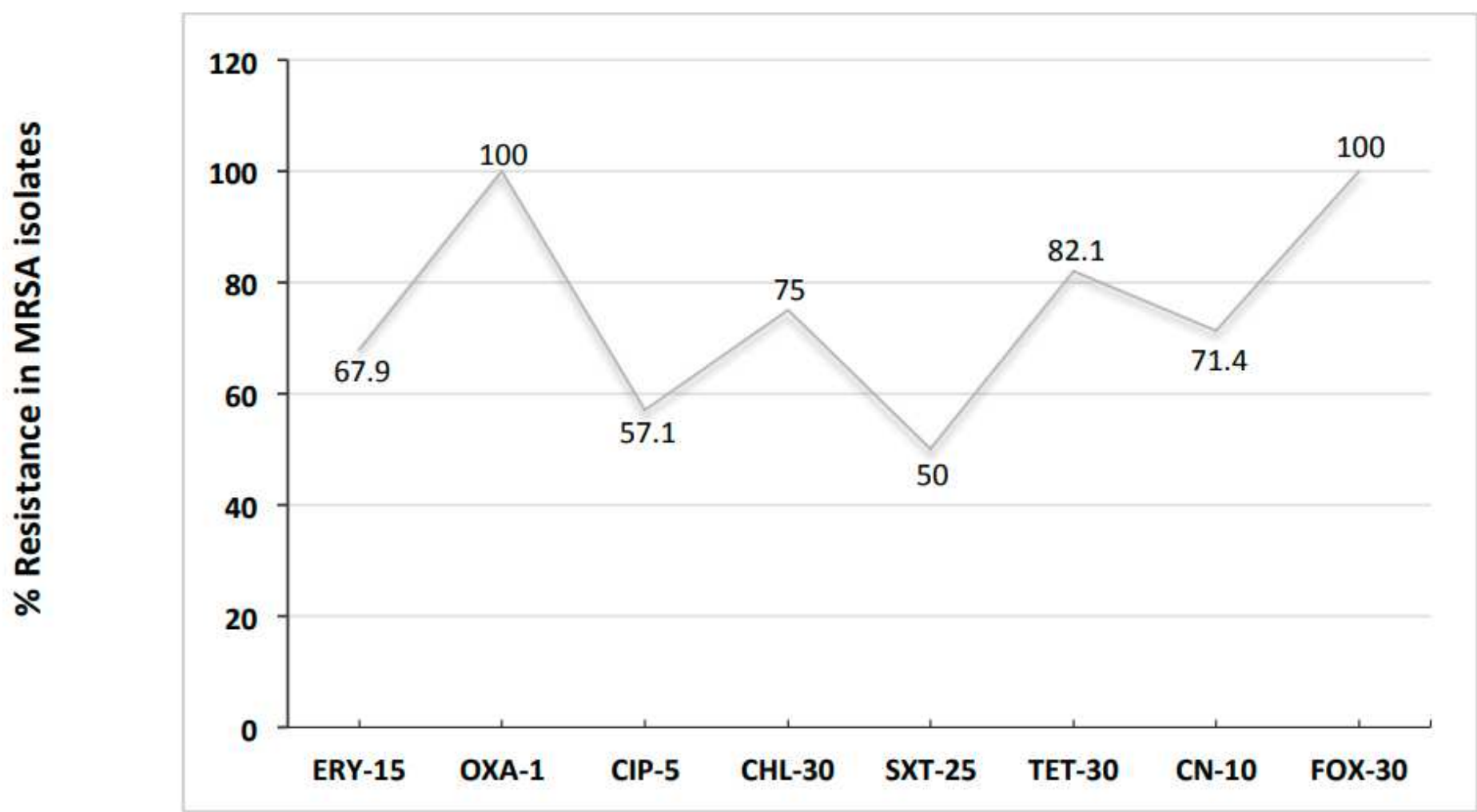

\section{Figure 1}

Antibiogram profile of the methicillin-resistant Staphylococcus aureus (MRSA) isolates. ERY-15:

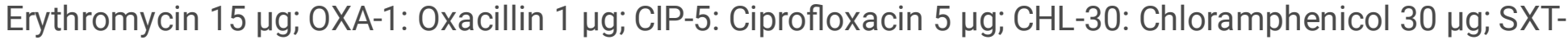
25 Trimethoprim-sulphamethoxazole 25ug; TET-30: Tetracycline 30ug; CN-10: Gentamycin 10ug; FOX-30: Cefoxitin-30ug. 


\section{$\begin{array}{llllllllll}\text { L } & 4 & \mathbf{8} & 20 & 21 & 38 & \text { tve } & \text {-ve }\end{array}$}

\section{0}

600

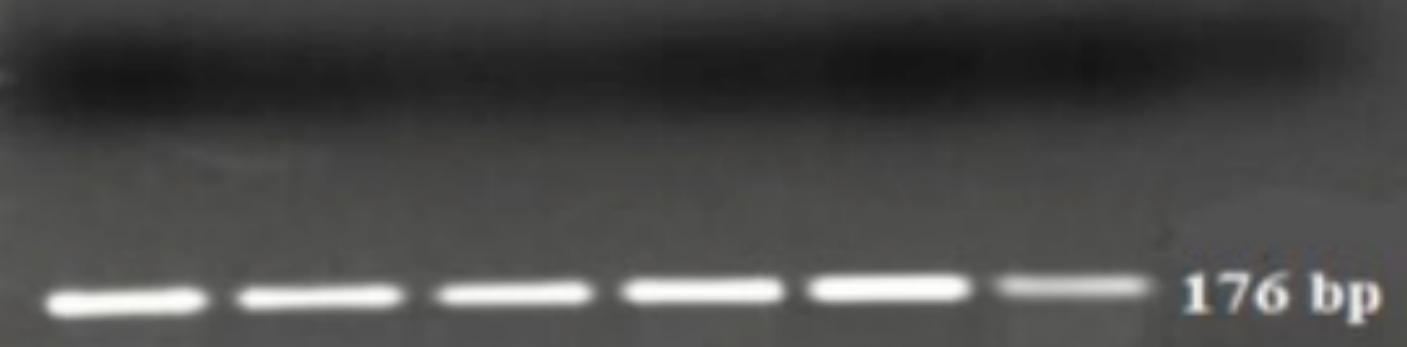

\section{0}

\section{Figure 2}

Electrophoretic gel image showing the $176 \mathrm{bp}$ PCR amplicon of the mecA gene in MRSA isolates. L: 100 bp DNA ladder; +ve: Positive control (S. aureus USA 300); -ve: RNase囚free water; 4 to 38; mec A positive S. aureus isolates

\section{Supplementary Files}

This is a list of supplementary files associated with this preprint. Click to download.

- BMCtable1togo.pdf

- BMCtable2togo.pdf 